Gut, 1971, 12, 284-290

\title{
An unusual case of self-induced electrolyte depletion
}

\author{
D. R. LOVE, J. J. BROWN, R. FRASER, A. F. LEVER, J. I. S. ROBERTSON, \\ G. C. TIMBURY, SHEENA THOMSON, AND M. TREE
}

From the MRC Blood Pressure Unit, Western Infirmary, Glasgow

SUMMARY A case of anorexia nervosa, presenting with unexplained hypokalaemia, is described. The patient was also secretly addicted to purgatives and diuretics. During an attempted metabolic balance study she secretly disposed of food and excreta, which were smuggled from the hospital by her sister. The patient induced her husband to bring his own stools into the ward, these then being substituted for her own.

The interrelationships of the electrolyte disturbances, elevation of plasma renin, renin substrate, and hyperaldosteronism are discussed, particularly in connexion with the pathogenesis of peripheral oedema in anorexia nervosa.

Anorexia nervosa is not infrequently associated with other psychiatric aberrations, which may be indulged in overtly or secretly by the patient. These include self-induced vomiting and addiction to purgatives and diuretics (Wolff, Vecsei, Krück, Roscher, Brown, Düsterdieck, Lever, and Robertson, 1968). The resultant biochemical disturbances may be profound, and the lack of a reliable history can make accurate diagnosis difficult.

We report here a further case of anorexia nervosa with secret addiction to purgatives and diuretics. The patient is especially interesting since there was active collusion with two of her relatives to obscure the diagnosis and confuse the result of hospital investigations.

\section{Methods}

Serum electrolytes were measured by AutoAnalyzer; urine electrolytes by the Eppendorf flame photometer; faecal electrolytes by flame photometry of a nitric acid digest of stools; plasma renin concentration was estimated by the method of Brown, Davies, Lever, Robertson, and Tree (1964) (normal range 4-20 units/litre); plasma renin substrate by the method of Tree (to be published) (normal range = 0.47 - $1.28 \times 10^{-6} \mathrm{M}$ ); plasma aldosterone concentration by a modification of the method of Fraser and James (1968) (normal range $<18 \mathrm{~m} \mu \mathrm{g} / 100 \mathrm{ml}$ ). Blood samples were taken from an arm vein between 09.00 and $10.00 \mathrm{hr}$ with the patient fasting and having remained supine since the previous evening, Received for publication 2 December 1970. forearm exercise being avoided (Brown, Chinn, Davies, Fraser, Lever, Rae, and Robertson, 1970). Total exchangeable sodium and potassium were measured by an isotope dilution technique (Davies, D. L. and Robertson, J. W. K., in preparation).

\section{Case History}

The patient was a 33-year-old married woman (date of birth 8 September 1936) with a congenital cleft lip and palate. Although these had been well repaired when she was a child, the resultant deformity caused her considerable unhappiness. Menstruation started at 10 years of age and she subsequently suffered from premenstrual ankle oedema. In 1953 she took up nursing and shortly afterwards developed acute appendicitis. For several months after the operation she complained of abdominal distension and discomfort; barium studies and an intravenous pyelogram at this time were, however, normal. Her weight in 1954 was $60 \mathrm{~kg}$.

Her marriage to a merchant seaman in 1962 was not a success, and one year later she consulted her doctor complaining of infertility, ankle swelling, polydipsia, and polyuria. Investigations in the local hospital were normal. During a readmission to hospital in 1966 for similar complaints she developed right-sided renal colic, and a calcium oxalate stone was removed from the right kidney. Following this operation, oedema became more troublesome and amenorrhoea developed. Frusemide was prescribed for the oedema in January 1967, and when the was next seen two days later carpopedal spasm with 


\begin{tabular}{|c|c|c|c|c|c|c|c|}
\hline & Jan 1967 & Feb 1967 & April 1968 & Sept 1968 & Oct 1968 & Nov 1968 & Nov 1969 \\
\hline $\begin{array}{l}\text { Serum } \mathrm{Na}^{+}(\mathrm{m} \text {-equiv/l) } \\
\text { Serum } \mathrm{K}(\mathrm{m} \text {-equiv/l) } \\
\text { Serum } \mathrm{Cl}(\mathrm{m} \text {-equiv/l) } \\
\text { Serum tCO, (m-equiv/l) } \\
\text { Serum urea }(\mathrm{mg} / 100 \mathrm{ml}) \\
\text { Serum } \mathrm{Ca}^{++}(\mathrm{mg} / 100 \mathrm{ml}) \\
\text { Urine } \mathrm{Na}^{+}(\mathrm{m} \text {-equiv/l) } \\
\text { Urine } \mathrm{K}^{+}(\mathrm{m} \text {-equiv/l) } \\
\text { Plasma renin (Units/l) } \\
\text { Plasma aldosterone }(\mathrm{m} \mu \mathrm{g} / \mathrm{ml}) \\
\text { Weight }(\mathrm{kg})\end{array}$ & $\begin{array}{c}136 \\
2 \cdot 4 \\
96 \\
32 \cdot 5 \\
25 \\
9 \cdot 9 \\
- \\
-\end{array}$ & $\begin{array}{c}138 \\
3 \cdot 3 \\
104 \\
- \\
17 \\
9 \cdot 2 \\
- \\
-\end{array}$ & $\begin{array}{c}139 \\
3 \cdot 0 \\
99 \\
23 \cdot 5 \\
21 \\
9 \cdot 5 \\
4 \\
4\end{array}$ & $\begin{array}{c}138 \\
2 \cdot 4 \\
98 \\
32 \cdot 5 \\
25 \\
9 \cdot 8 \\
2 \\
6 \\
93 \\
9 \cdot 8 \\
45\end{array}$ & $\begin{array}{l}141 \\
3 \cdot 5 \\
95 \\
30 \cdot 5 \\
27 \\
10 \\
1 \\
3 \\
\\
46\end{array}$ & $\begin{array}{l}141 \\
2 \cdot 6 \\
98 \\
30 \cdot 5 \\
28 \\
- \\
-\end{array}$ & $\begin{array}{r}127 \\
5 \cdot 5 \\
90 \\
13 \\
130 \\
-1 \\
1 \\
50 \\
418 \\
89 \\
32\end{array}$ \\
\hline
\end{tabular}

Table I Biochemical data obtained as an outpatient from January 1967-April 1968 and representative values during the first two admissions (September 1968 and on third admission November 1968)

positive Chvostek's and Trousseau's signs had developed. Marked hypokalaemia and a slightly raised level of $\mathrm{tCO}_{2}$ were also present (Table I). Although her symptoms improved the hypokalaemia persisted and potassium supplements were prescribed in February 1967.

Because of the patient's reluctance to be readmitted to hospital, further investigation was not possible until April 1968, when, during a brief admission, the hypokalaemia was associated with very low urinary potassium concentration (Table I).

FIRST ADMISSION TO WESTERN INFIRMARY, GLASGOW

In September 1968 the patient was referred to this hospital for further investigation. Her symptoms were essentially as before, but she was also complaining of constipation and tingling of the extremities. She emphatically denied taking diuretics or purgatives. On examination, she weighed $45 \mathrm{~kg}$ and Trousseau's sign was positive. Clinical examination was otherwise unremarkable.

Again the combination of marked hypokalaemia and low urinary potassium concentrations was demonstrated (Table I). Plasma renin concentration was high at 93 units/litre, although plasma aldosterone was normal at $9.8 \mathrm{~m} \mu \mathrm{g} / 100 \mathrm{ml}$.

\section{First metabolic balance study}

A metabolic balance study was begun and the patient appeared to cooperate well. She did not refuse food and she was not seen to vomit. The stools collected were well formed. Potassium balance appeared markedly positive, with intake greatly exceeding output in urine and stools (Fig. 1). Nevertheless, hypokalaemia persisted. The sodium balance was also apparently strongly positive (Fig. 1), but there was still no increase in weight. These anomalies led to the suspicion that the patient was not cooperating fully, but before the matter could be pursued she insisted on returning home, ostensibly because of domestic problems.
SECOND ADMISSION TO WESTERN INFIRMARY, GLASGOW

Two weeks later (October 1968) she was readmitted as an emergency with carpopedal spasm and hyperventilation. Mild hypokalaemia and low urinary potassium concentration were again present (Table I). She recovered spontaneously, but refused to stay in hospital for further investigations. She was allowed home and given oral potassium supplements (26 m-equiv/day).

Follow-up appointments were not kept, but one year later, coincident with the return of her husband from sea, she developed anorexia and diarrhoea. Six weeks later persistent vomiting developed and she was readmitted as an emergency (November 1969).

THIRD ADMISSION TO WESTERN INFIRMARY, GLASG OW

On examination she looked extremely ill and dehydrated and her weight was only $32 \mathrm{~kg}$. Blood pressure was $85 / 60 \mathrm{~mm} \mathrm{Hg}$ lying and $70 / 40 \mathrm{~mm} \mathrm{Hg}$ standing. There was no abnormal pigmentation and pubic and axillary hair were normal. The serum and urine electrolytes, serum urea and plasma renin and aldosterone concentration on admission are shown in Table I. Plasma 11-hydroxycorticoids showed a normal diurnal rhythm, and the response to $0.25 \mathrm{mg}$ of synthetic ACTH (Tetracosactrin) given intramuscularly was normal (basal 11 OHCS $=11.5 \mu \mathrm{g}$ / $100 \mathrm{ml} ; 30 \mathrm{~min}$ after Tetracosactrin $=30.5 \mu \mathrm{g} /$ $100 \mathrm{ml}$ ). Also normal were the blood count, chest and skull radiographs, serum protein-bound iodine, barium meal and follow through, barium enema, sigmoidoscopy, and repeated culture of stools.

The patient was confined to a single room and encouraged to eat. She was closely supervised and appeared to cooperate well. However, the day after admission a foul smell was traced to a suitcase in the patient's room and on inspection (unknown to the patient) this was found to contain numerous paper and polythene parcels, each containing par- 


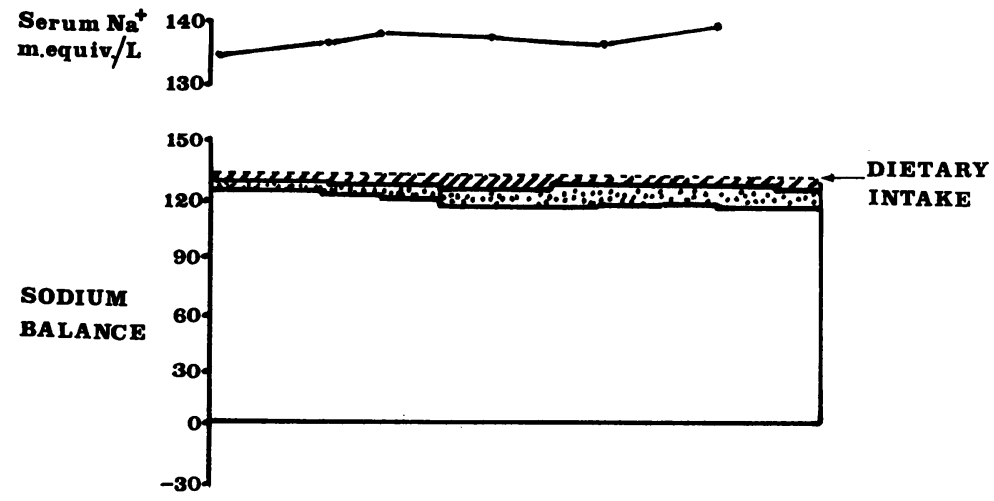

Fig. 1. First metabolic balance study Sept. 1968. Output of electrolytes in urine (hatched) and stool (stippled) is plotted downwards from dietary intake. The plain area thus represents positive external balance.
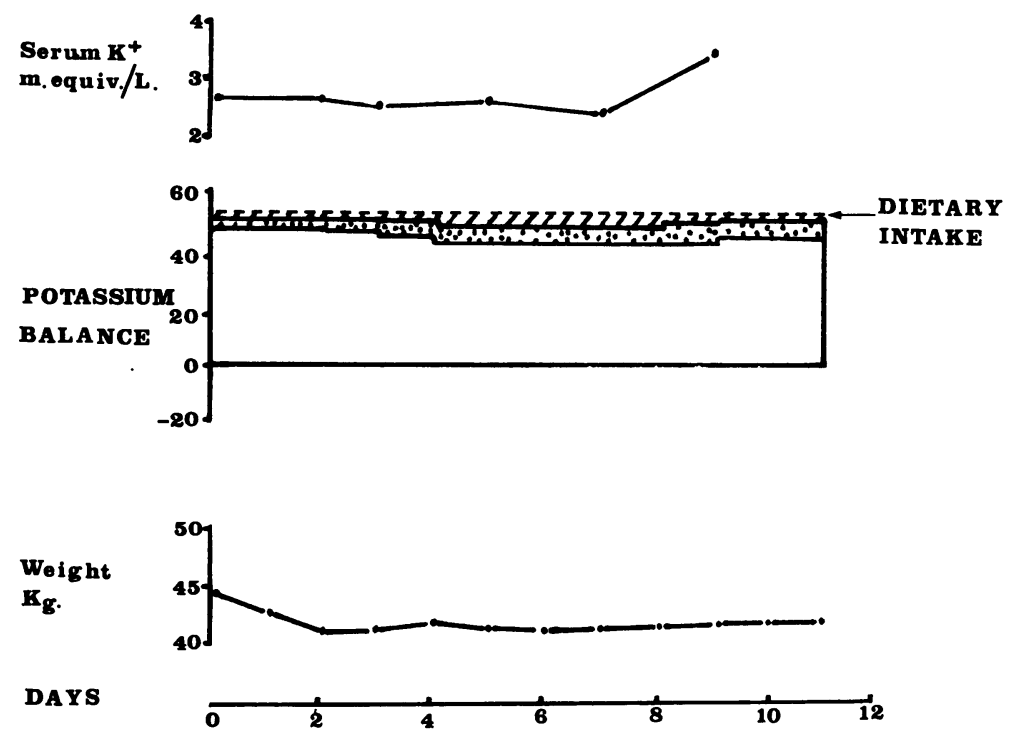

tially digested food, vomitus, and liquid faeces. The contents of the case were replaced and later that day it was collected by the patient's sister.

Some days later the patient's husband revealed that he had found several empty bisacodyl (Dulcolax) cartons hidden in his wife's bedroom, and her mother produced the bill for 3,000 tablets which indicated that they had been purchased only three weeks earlier. In a further interview the husband confessed that during the first metabolic balance in September 1968 (data in Figure 1) his wife had been hiding her food and stools, which had then been smuggled out of the ward by her sister. Realizing that she would have to produce faeces for the metabolic balance, the patient persuaded her husband to bring into the ward his own stools which were then offered as part of the metabolic balance. Thus, of the data in Figure 1, the stool electrolytes, which were normal, properly belong to the husband and the urine electrolytes to the wife. Electrolyte intake was almost certainly a gross overestimate because the sister had disposed of uneaten food.

Second metabolic balance study (November 1969)

A second metabolic balance study was attempted and the results are shown in Figure 2. On this occasion the patient was confined to her room, food was given under strict supervision, and all urine and faeces were passed into a commode under observation so that secret disposal was less likely. Although she again appeared to be cooperative, she attempted to obtain purgatives from other patients and nurses and her mother intercepted a letter to the chemist requesting a further supply of Dulcolax to be sent urgently. On other occasions the patient was found heating her thermometer on a radiator, and emptying salt into a disposal bag.

On admission, the serum potassium concentration 


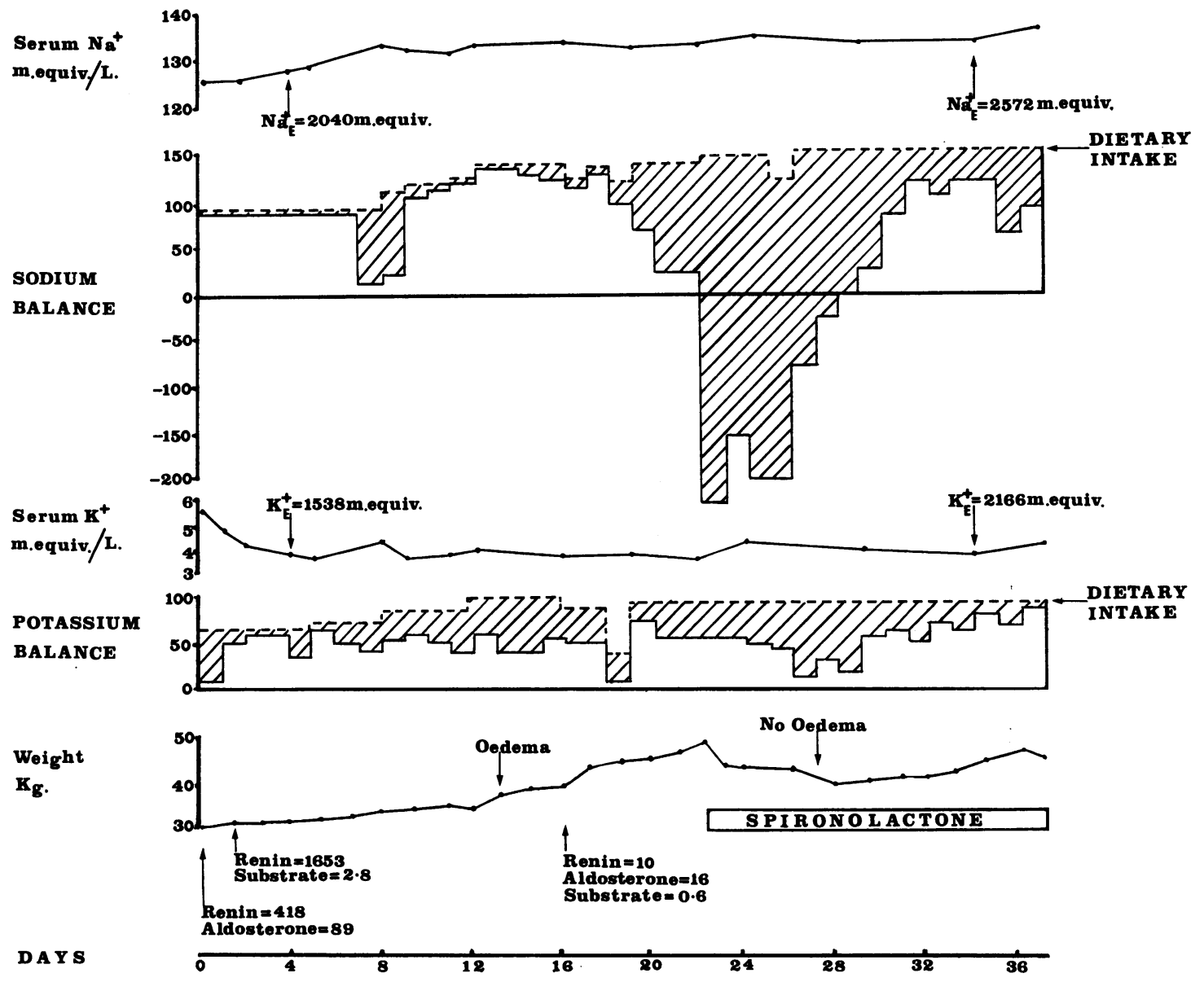

Fig. 2. Second metabolic balance study Nov.-Dec. 1969. Output of electrolytes in urine (hatched) is plotted downwards from dietary intake. Where this is less than intake the plain area above zero represents positive external balance, and when urine electrolytes exceed intake the hatched area below zero represents negative external balance. Several estimations of three-day stool electrolytes showed that they did not contribute significantly to the overall balance, and are therefore not shown in this figure. Plasma renin concentration units/l; renin substrate moles $\times 10^{-6}$ aldosterone mug/ $100 \mathrm{ml}$.

was remarkably high (Table I). Possible explanations include excessive intake of potassium supplements, metabolic acidosis, and increased tissue catabolism. However, high serum potassium concentrations may sometimes occur with depletion of total body potassium (Moore, Edelman, Olney, James, Brooks, and Wilson, 1954; Flear, Quinton, Carpenter, Domenet, and Sivyer, 1966), and this may have been the case in our patient, as serum potassium fell rapidly after admission despite a positive potassium balance (Fig. 2). Also total exchangeable potassium rose by $628 \mathrm{~m}$-equiv during a period in which serum potassium concentration fell (Fig. 2). On this occasion there was marked hyponatraemia, urinary losses of sodium were negligible, and total exchangeable sodium was low in relation to the value after refeeding (Fig. 2). The plasma concentrations of renin and aldosterone were both raised (418 units/ litre and $89 \mathrm{~m} \mu \mathrm{g} / 100 \mathrm{ml}$ respectively) as in other states of sodium depletion (see Brown, Davies, Lever, and Robertson, 1966; Fraser, Brown, Chinn, Lever, and Robertson, 1969). It is of interest to note that on this occasion, in contrast to September 1968, an increase in plasma renin concentration was accompanied by an increase in plasma aldosterone (Table I). High plasma renin was also associated with high renin substrate, similar to the situation in some patients with severe renal failure (Brown, Düster- 
diek, Fraser, Lever, Robertson, Tree, andWeir, 1971).

With refeeding, sodium was retained to a marked degree associated with a gain in weight (Fig. 2). After 12 days ankle and leg oedema developed; at this time plasma renin, renin substrate, and aldosterone had returned to normal. Spironolactone, $200 \mathrm{mg} /$ day, given orally from the 22nd day onwards, produced a brisk natriuresis and loss of oedema (Fig. 2).

After 33 days of treatment the patient was greatly improved. She was free from oedema and had gained $11 \mathrm{~kg}$ in weight. Serum electrolytes were normal and both total exchangeable sodium and potassium had increased (Fig. 2). However, it is interesting that the cumulative balance of sodium, as calculated from the metabolic balance $(+1,800$ m-equiv), was considerably greater than the increase as measured by the change in total exchangeable sodium $(+532$ m-equiv). Similarly, the cumulative potassium gain as calculated from the external balance was in excess of the change of total exchangeable potassium $(+1,810$ m-equiv and +628 m-equiv respectively). A possible explanation of these discrepancies is that despite our efforts, the patient was still managing to dispose of food or excreta.

\section{Psychiatric Features}

The patient was first seen by a psychiatrist in November 1969. During the course of five interviews the most striking feature of her mental state was the apparent unconcern at her serious physical plight and her reluctance to discuss her marriage or other possibly relevant topics of emotional difficulty. The history suggested that she was of above average intelligence and no evidence could be elicited of psychiatric illness other than that manifested by the disturbance of her behaviour described above. She did not admit to conscious fears of weight gain, nor were psychotic features discerned. She could give no satisfactory explanation of her unusual behaviour in the ward even when confronted with this. Followup was unsatisfactory. She was unwilling to enter a psychiatric hospital or later to attend a psychiatric day hospital. She did not keep an appointment with a clinical psychologist.

\section{Discussion}

\section{ELECTROLYTE DEPLETION IN ANOREXIA} NER VOSA

The electrolyte disturbances observed in this patient were produced by a combination of deficient food intake, secret abuse of purgatives and diuretics, and vomiting. Excessive purgation may not only cause severe potassium depletion (Schwartz and
Relman, 1953; Houghton and Pears, 1958;Aitchison, 1958; Litchfield, 1959; De Graeff and Schuurs, 1960) but it may also cause considerable sodium loss (Coghill, McAllen, and Edwards, 1959). Diuretics, likewise, cause depletion of sodium and potassium. As a probable consequence of sodium depletion, secondary hyperaldosteronism has also been encountered in anorexia nervosa (Wolff et al, 1968; Pasternack, 1970). In the present patient the predominant electrolyte abnormality throughout was hypokalaemia although hyponatraemia was also present during the last admission. These abnormalities have been encountered in other patients of this type, and the importance of multiple routes of electrolyte loss and their interrelationship has been emphasized (Wolff et al, 1968).

\section{PSYCHOLOGICAL FEATURES}

The psychological features of anorexia nervosa have been reviewed by Crisp (1967) and by Dally (1969). Many writers have drawn attention to the similarity of the mental state of these patients to that of hysteria, phobic states, depression, or schizophrenia. This patient's unusual behaviour, the manipulation of her family and medical advisers, and the superficial similarity to other patients who indulge in self-injury, is reminiscent of the cases of 'deliberate disability' described by Hawkings, Jones, Sims, and Tibbetts (1956) and patients with Munchhausen's syndrome (Asher, 1951). The present subject's adjustment to her early facial disfigurement, her choice of a nursing career, and her marriage to a man who was away from home for long periods, are all probably significant factors in the development of her illness. The long medical history suggests that she had obtained some vicarious emotional satisfaction by adopting the role of an invalid.

Her ability to elicit the active collaboration of various relatives in her attempts to deceive the medical attendants is noteworthy. Gull (1874) stressed that 'the patients should be .... . surrounded by persons who would have moral control over them, relations and friends being generally the worse attendants'. Clearly, he was well aware of the dangers of such proximity. However, he does not record such bizarre happenings as we encountered in this woman.

The prognosis in anorexia nervosa is generally held to be poor (Kay, 1953; Crisp, 1965).

RELATION BETWEEN RENIN, ALDOSTERONE, AND POTASSIUM

Usually an increase in plasma renin concentration is associated with an increase in plasma aldosterone (Fraser et al, 1969). This was certainly so during the third admission (Fig. 2). However, during the 
first admission a raised plasma renin concentration was associated with a normal plasma aldosterone concentration (see Table I). This unusual finding may be explained by the marked hypokalaemia present at that time. Potassium depletion or hypokalaemia is known to depress aldosterone secretion (Cannon, Ames, and Laragh, 1966). Thus the stimulant effect of the elevated plasma renin may have been attenuated by hypokalaemia, although in our earlier study (Wolff et al, 1968) there was no evidence for an effect of this sort. It is interesting to note that in November 1969 (Table I), when hypokalaemia was not present, elevation of plasma renin concentration was accompanied by an appropriate increase in plasma aldosterone.

\section{ALDOSTERONE AND RENAL POTASSIUM CONSERVATION}

Aldosterone promotes sodium retention and potassium loss in the urine. Despite increased concentrations of plasma aldosterone in this patient during the admission of November 1969, urinary potassium concentration was usually low (see Fig. 2). This phenomenon has been observed previously. If normal subjects taking an unrestricted diet are given sodium-retaining steroids sodium retention and potassium depletion result (August, Nelson, and Thorn, 1959). However, when sodium-retaining steroids are given during sodium deprivation, potassium depletion does not occur (Seldin, Welt, and Cort, 1951; Dawborn, 1969). A possible explanation is that in conditions of sodium depletion most of the filtered sodium is reabsorbed in the proximal part of nephrons, little reaching the distal tubules for exchange with potassium. Thus, the amount of potassium which can appear in the urine may be limited during sodium depletion, despite raised aldosterone levels. We have previously noted in similar patients efficient renal conservation of potassium in the face of raised aldosterone levels (Wolff et al, 1968). The finding of extremely low urinary potassium concentrations may have considerable clinical diagnostic value in cases of unexplained hypokalaemia, indicating extrarenal potassium loss.

OEDEMA IN ANOREXIA NERVOSA

Oedema is a common finding in anorexia nervosa (Gull, 1874; Kidd and Wood, 1966; Wolff et al, 1968; Dally, 1969) and is particularly common when the patient is admitted to hospital and refed (De Graeff and Schuurs, 1960; Dally and Sargant, 1966). Oedema was prominent in this patient and was particularly marked during refeeding. There are several reasons why oedema may occur in anorexia nervosa. The oedema and sodium retention observed during refeeding were probably the result of the extremely high levels of renin and aldosterone at that time. However, positive sodium balance and worsening of the oedema continued after plasma renin and aldosterone concentrations had fallen to normal. The mechanism of this continuing sodium retention with normal aldosterone levels is not known, but it has also been observed in fasted obese subjects (Walker, Cooke, and Turin, 1969; Chinn, Brown, Fraser, Heron, Lever, Murchison, and Robertson, 1970). Aldosterone, even in normal concentration, may still be exerting a sodiumretaining effect in this situation, and the efficacy of spironolactone in the present case (Fig. 2) offers some support for this view. Alternatively, other sodium-retaining steroids (or mechanisms) may be operative.

Another possible reason for oedema is the common occurrence of hypokalaemia in anorexia nervosa. Fourman (1954) has shown that experimental potassium depletion in normal subjects may be associated with oedema, and oedema has also been observed in purgative addicts who are also potassium depleted (Coghill, McAllen, and Edwards, 1959; Heizer, Warshaw, Waldmann, and Laster, 1968). However, this explanation is unlikely in the present patient, because at the time when oedema was most marked there was no evidence of potassium depletion.

It is interesting that our patient suffered from cyclical or premenstrual oedema for many years before she developed other symptoms. Patients with cyclical oedema (Thorn, 1957) share many characteristics with those suffering from anorexia nervosa. Both conditions occur almost exclusively in women who are often emotionally unstable and frequently have some association with the medical or nursing professions. The two groups of patients also have an impaired ability to excrete a water load in the upright position, although they may do so normally when recumbent (Russell and Bruce, 1966; Thorn, 1968). Although the pathogenesis of cyclical oedema is not known, it is possible that similar fluid-retaining mechanisms to those of anorexia nervosa may be at work.

Dr D. R. Love was in receipt of a grant from the D. W. T. Cargill Trust Fund during this study. We thank Dr G. Watkinson for his advice.

\footnotetext{
References

Aitchison, J. D. (1958). Hypokalaemia following chronic diarrhoea from overdue of cascara and a deficient diet. Lancet, 2 75-76. Asher, R. (1951). Munchhausen's syndrome. Lancet, 1, 339-341.

August, J. T., Nelson, D. H., and Thorn, G. W. (1958). Response of normal subjects to large amounts of aldosterone. $J$. clin. Invest., 37, 1549-1555.
} 
Brown, J. J., Chinn, R. H., Davies, D. L., Fraser, R., Lever, A. F., Rae, R. J., and Robertson, J. I. S. (1970). Falsely high plasma potassium values in patients with hyperaldosteronism. Brit. med. J., 2, 18-20.

Brown, J. J., Davies, D. L., Lever, A. F., Robertson, J. I. S., and Tree, M. (1964). The estimation of renin in human plasma. Biochem. J., 93, 594-600.

Brown, J. J., Davies, D. L., Lever, A. F., and Robertson, J. I. S. (1966). Renin and angiotensin; a survey of some aspects. Postgrad. med. J., 42, 153-176.

Brown, J. J., Düsterdiek, G., Lever, A. F., Robertson, J. I. S., Tree, M., and Weir, R. J. (1971). Hypertension and chronic renal failure. Brit. med. Bull., 23, in press.

Cannon, P. J., Ames, R. P., and Laragh, J. H. (1966). Relation between potassium balance and aldosterone secretion in normal subjects and in patients with hypertensive or renal tubular disease. J. clin. Invest., 45, 865-879.

Chinn, R. H., Brown, J. J., Fraser, R., Heron, Sheila M., Lever, A. F., Murchison, Lilian, and Robertson, J. I. S. (1970). The natriuresis of fasting: relationship to changes in plasma renin and plasma aldosterone concentrations. Clin. Sci., 39, 437-455.

Coghill, N. F., McAllen, P. M., and Edwards, F. (1959). Electrolyte loss associated with the taking of purges investigated with aid of sodium and potassium radioisotopes. Brit. Med.J., 1, 14-19.

Crisp, A. H. (1965). Clinical and therapeutic aspects of anorexia nervosa-a study of 30 cases. J. psychosom. Res, 9, 67-78.

Crisp, A. H. (1967). Anorexia nervosa. Brit. J. hosp. Med., 1 713-718.

Dally, P. (1969). Anorexia Nervosa. Heinemann, London.

Dally, P., and Sargant, W. (1966). Treatment and outcome of anorexia nervosa. Brit. med. J., 2, 793-795.

Dawborn, J. K. (1969). The effect of prolonged intravenous infusion of aldosterone in a normal human subject. Med. J. Aust., $1,1079-1083$.

De Graeff, J., and Schuurs, M. A. M. (1960). Severe potassium depletion caused by the overabuse of laxatives. Acta med.scand., $166,407-422$.

Flear, C. T. G., Quinton, A., Carpenter, R. C., Domenet, J. C., and Sivyer, A. (1966). Exchangeable body potassium and codium in patients in congestive heart failure. Clin.chim. Acta., 13, 1-12.

Fourman, P. (1954). Depletion of potassium indeced in man with an exchange resin. Clin.Sci., 13, 93-110.

Fraser, R., and James, V. H. T. (1968). Double isotope assay of aldosterone, corticosterone and cortisol in human peripheral plasma. J. Endocr., 40, 59-72.

Fraser, R., Brown, J. J., Chinn, R. H., Lever, A. F., and Robertson, J. I. S. (1969). The control of aldosterone secretion and its relationship to the diagnosis of hyperaldosteronism. Scot. med. J., 14, 420-440.

Gull, W. W. (1874). Anorexia nervosa (apepsia hysterica, anorexia hysterica). Trans. clin. Soc. (Lond.), 7, 22-28.

Hawkings, J. R., Jones, K. S., Sim, M., and Tibbetts, R. W. (1956). Deliberate disability. Brit. med. J., 1, 361-367.

Heizer, W. D., Warshaw, A. L., Waldmann, T. A., and Laster, L. (1968). Protein-losing gastroenteropathy and malabsorption associated with factitious diarrhea. Ann. intern Med., 68, 839-852.

Houghton, B. J., and Pears, M. A. (1958). Chronic potassium depletion due to purgation with cascara. Brit. med.J., 1, 1328-1330.

Kay, D. W. K. (1953). Anorexia nervosa: a study in prognosis. Proc. roy. Soc. Med., 46, 669-674.

Kidd, C. B., and Wood, J. F. (1966). Some observations on anorexia nervosa. Postgrad. med. J., 42, 443-448.

Litchfield, J. A. (1959). Low potassium syndrome resulting from the use of purgative drugs. Gastroenterology, 37, 483-488.

Moore, F. D., Edelman, I. S., Olney, J. M., James, A. H., Brooks, L. and Wilson, G. M. (1954). Body sodium and potassium III. Interrelated trends in alimentary, renal, and cardiovascular disease: lack of correlation between body stores and plasma concentration. Metabolism, 3, 334-350.

Pasternack, A. (1970). Anorexia nervosa, secondary aldosteronism and angiopathy. Acta med. scand., 187, 139-143.

Russell, G. F. M., and Bruce, J. T. (1966). Impaired water diuresis in patients with anorexia nervosa. Amer. J. Med., 40, 38-48.

Schwartz, W. B., and Relman, A. S. (1953). Metabolic and renal studies in chronic potassium depletion resulting from overuse of laxatives. J. clin. Invest., 32, 258-271.

Seldin, D. W., Welt, L. G., and Cort, J. (1951). The effect of pituitary and adrenal hormones on the metabolism and excretion of potassium. J. clin. Invest., 30, 673.

Thorn, G. W. (1957). Cyclical ofdema. Amer. J. Med., 4, 507-5C9.

Thorn, G. W. (19t8). Approach to the patient with 'idiopathic edema' or 'periodic swelling'. J. Amer. med. Ass., 206, 333-338.

Walker, W. G., Cooke, C. R and Turin, M. (1969). Sustained sodium retention not mediated by aldosterone (abstr.). In Proceedings of the IVth International Congress of Nephrology, Stockholm, vol. 1, p. 432.

Wolff, H. P., Vecsei, P., Krück, F., Roscher, S., Brown, J. J., Düsterdieck, G. O., Lever, A. F., and Rotertson, J. I. S. (1968). Psychiatric disturbance leading to potassium depletion, sodium depletion, raised plasma-renin concentration, and secondary hyperaldosteronism. Lancet, 1, 257-261. 